\title{
Survey of Canadian Pharmacists' Responses to Warnings of Potential Interactions Between Ceftriaxone and Calcium in IV Solutions
}

\author{
Curtis K Harder and John J Hawboldt
}

\begin{abstract}
Background: In 2007, because of a potential interaction between ceftriaxone and calcium-containing IV solutions, Roche Laboratories (manufacturer of Rocephin [ceftriaxone] in the United States) issued letters to health care professionals advising them of changes to the product monograph. Subsequently, warning letters were also issued by the US Food and Drug Administration (FDA) and Health Canada. The Health Canada recommendations and their implications for clinical practice generated debate in the Canadian hospital pharmacy community.
\end{abstract}

Objective: To evaluate the response to the warnings among hospital pharmacists and their respective institutions.

Methods: An anonymous, voluntary 10-question survey was distributed to members of the Pharmacy Specialty Networks of the Canadian Society of Hospital Pharmacists. Requests to participate were solicited via 2 e-mail messages. Responses were analyzed descriptively.

Results: A total of 152 pharmacists participated in the survey. Fortythree respondents $(28.3 \%)$ reported being very concerned and 86 (56.6\%) reported being somewhat concerned about the Health Canada Notice to Hospitals. About half (77/152 [50.7\%]) of the respondents felt that the Health Canada notice did not need to be strictly heeded. Two-thirds (98/145 [67.6\%]) reported that their institutions had addressed the risk of an interaction through a change in policy regarding the administration of ceftriaxone. Eighty-eight (61.5\%) of 143 participants indicated that their institution's official position on the notice was that it represented a "relative contraindication" (i.e., the benefit may outweigh the risk).

Conclusions: Warning letters issued by the manufacturer, the FDA, and Health Canada generated concern within the Canadian hospital pharmacy community. However, a large proportion of hospital pharmacy practitioners did not agree with strict adherence to the Health Canada notice.

Key words: ceftriaxone, calcium, administration, precipitation

Can J Hosp Pharm 2009;62(6):483-489

\section{RÉSUMÉ}

Contexte : En 2007, à cause d'une interaction potentielle entre la ceftriaxone et les solutions intraveineuses contenant du calcium, Roche Laboratories (fabricant de Rocephin [ceftriaxone] aux États-Unis) ont émis une mise en garde aux professionnels de la santé les informant d'une modification à la monographie du produit. Par la suite, des mises en garde ont également été émises par la Food and Drug Administration (FDA) des États-Unis et par Santé Canada. Les recommandations de Santé Canada et leurs conséquences sur la pratique clinique ont soulevé un débat au sein de la communauté de la pharmacie hospitalière.

Objectif : Évaluer la réponse à la mise en garde parmi les pharmaciens d'hôpitaux et leurs établissements respectifs.

Méthodes : Un sondage anonyme à participation volontaire comportant 10 questions a été remis aux membres des Réseaux de spécialistes en pharmacie de la Société canadienne des pharmaciens d'hôpitaux. Les invitations à participer au sondage ont été communiquées au moyen de deux courriels. Les réponses ont été analysées de façon descriptive.

Résultats : Au total, 152 pharmaciens ont participé au sondage. Quarante-trois répondants $(28,3 \%)$ ont déclaré être très préoccupés et $86(56,6 \%)$ ont déclaré être quelque peu préoccupés par l'Avis aux hôpitaux de Santé Canada. Environ la moitié (77/152 [50,7\%]) des répondants estimaient qu'il n'était pas nécessaire de suivre à la lettre l'avis de Santé Canada. Les deux-tiers (98/145 [67,6\%]) ont déclaré que leur établissement avait pris des mesures contre le risque d'interaction en modifiant leur politique d'administration de la ceftriaxone. Par ailleurs, $88(61,5 \%)$ de 143 répondants ont indiqué que la position officielle de leur établissement relativement à cet avis était que celui-ci représentait une " contre-indication relative » (c.-à-d. que les bienfaits pouvaient l'emporter sur le risque).

Conclusions : Les mises en garde émises par les fabricants, par la FDA et par Santé Canada ont soulevé des inquiétudes au sein de la communauté des pharmaciens d'hôpitaux du Canada. En revanche, une forte proportion des praticiens de la pharmacie hospitalière n'étaient pas d'accord pour observer à l'avis de Santé Canada.

Mots clés : ceftriaxone, calcium, administration, précipitation

[Traduction par l'éditeur] 


\section{INTRODUCTION}

Ceftriaxone, a third-generation cephalosporin with a broad spectrum of antimicrobial activity, is useful for treating a wide range of infections. ${ }^{1}$ The drug is highly bound to protein ( $85 \%$ to $95 \%$ ) and is eliminated primarily by renal excretion (50\%) and hepatic metabolism (40\%). ${ }^{2}$ Ceftriaxone is less soluble than other cephalosporins, and precipitation has been known to occur, a process resulting in a condition known as "biliary sludge". ${ }^{3}$ This problem is especially of concern in neonates with hyperbilirubinemia, in whom ceftriaxone may cause additional displacement of bilirubin from protein binding sites, which further elevates serum concentrations of unbound bilirubin. ${ }^{4}$ Biliary sludging, lithiasis, and nephrolithiasis have occurred in both pediatric and adult patients, and it has been suggested that the mechanism of these phenomena is related to the formation of a precipitant involving ceftriaxone and calcium. ${ }^{5,6}$

Postmarketing reports by the manufacturer of ceftriaxone (Rocephin; Roche Laboratories, Nutley, New Jersey) identified 5 cases of neonatal death related to ceftriaxone-calcium precipitates. ${ }^{5}$ In 4 of these cases, the ceftriaxone and calcium had been administered through the same IV line; in the fifth case, the 2 agents had been administered at different sites and different times (although the exact time difference was not reported). Two of the reports noted that precipitates were identified in the pulmonary and renal vasculature at autopsy. The US Food and Drug Administration (FDA) identified in its own records an additional 4 reports of interactions between ceftriaxone and calcium in children up to 1 year of age. ${ }^{5}$ Three of these children died, and an autopsy revealed crystals in the lungs of one of them. The source of the calcium was either calcium gluconate or total parenteral nutrition solution containing calcium. ${ }^{7}$ To date, there have been no reports of such intravascular precipitation in patients older than 1 year undergoing concurrent treatment with ceftriaxone and calcium-containing IV solutions.

In summer 2007, the manufacturer issued letters to health care professionals, advising them of updates in the contraindications, warnings, precautions, adverse reactions, and dosage and administration sections of the product monograph. ${ }^{8}$ Subsequently, the $\mathrm{FDA}^{5}$ and Health Canada ${ }^{1}$ issued related warnings about the use of ceftriaxone and calcium-containing IV solutions (in July 2007 and July 2008, respectively). Of greatest relevance to Canadian practitioners, the Health Canada Notice to Hospitals specified that for patients under 10 weeks of age, IV ceftriaxone and calcium-containing IV solutions should not be administered within 5 days of one another. ${ }^{1}$ For all other patients, the notice recommended that IV ceftriaxone and calcium-containing IV solutions should not be administered within $48 \mathrm{~h}$ of one another. ${ }^{1}$ In addition, ceftriaxone and calcium-containing IV solutions, including calcium-containing solutions for continuous infusion, as for parenteral nutrition, should not be mixed or coadministered to any patient, irrespective of age, even through different infusion lines at different sites. ${ }^{1}$

Given an international shortage of cefotaxime (an alternative to ceftriaxone) in 2008, these warnings and recommendations generated substantial discussion in the hospital pharmacy community with respect to their application in clinical practice. The purpose of this study was to assess the opinions and responses of pharmacists and their respective institutions regarding warnings of the calcium-ceftriaxone interaction.

\section{METHODS}

A 10-question online survey (Appendix 1) was developed in consultation with members of the Canadian Society of Hospital Pharmacists (CSHP) Executive Committee for the Infectious Diseases Pharmacy Specialty Network (PSN). The survey was conducted within existing CSHP PSNs between October 15 and October 31, 2008. Eligible participants were members of one or more PSNs, and participation was anonymous and voluntary. The chairperson of each PSN was asked to solicit responses from members of his or her PSN by sending an initial e-mail request and a midpoint e-mail reminder on behalf of the study investigators. Communication to PSN members about the survey was not enforced by the study investigators. Responses were collected and tabulated using a proprietary online survey tool (SurveyMonkey.com). The survey results were analyzed descriptively.

\section{RESULTS}

A total of 152 pharmacists from 9 provinces and 1 territory participated in the survey (Figure 1). Prince Edward Island, the Northwest Territories, and Nunavut were not represented. The largest proportion of respondents was from Ontario (64/152 [42.1\%]), followed by Alberta (22/152 [14.5\%]), British Columbia, and Nova Scotia (17/152 each [11.2\%]). The majority of participants represented individual hospitals (114/152 [75.0\%]), evenly divided between teaching or tertiary care and community or general hospitals. Two participants commented that they represented pediatric hospitals. Since some respondents did not answer all of the survey questions, the denominator for some of the questions was less than 152 .

When asked about their level of concern regarding the Health Canada and manufacturer warnings, the vast majority of respondents (149/152 [98.0\%]) indicated that they had an opinion, with responses ranging from "unconcerned" to "very concerned". Of the $129(84.9 \%)$ respondents who had concerns, $43(33.3 \%)$ were very concerned and $86(66.7 \%)$ 


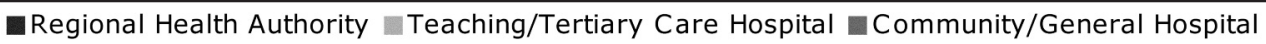

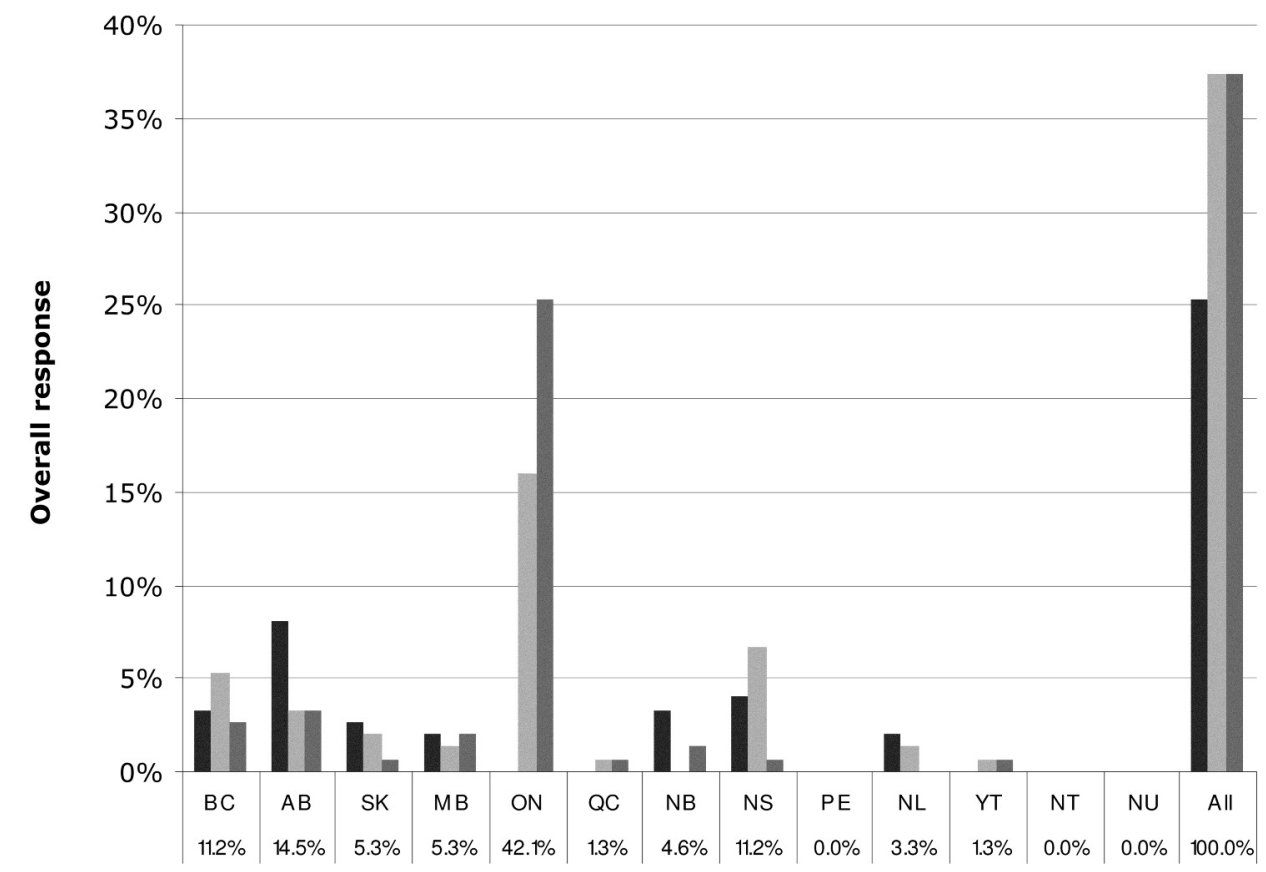

$\%$ response by province

Figure 1. Responses to a survey about warnings of interactions between ceftriaxone and calcium in IV solutions, according to geographic location and institutional affiliation.

were somewhat concerned. However, only 39 (25.7\%) of the 152 respondents agreed that the 48 -h window for calcium avoidance described in the Health Canada Notice to Hospitals should be strictly heeded (Figure 2). Of these 39 respondents, $24(61.5 \%)$ agreed and $15(38.5 \%)$ strongly agreed with strict adherence to the 48-h window. In contrast, about half (77 [50.7\%]) of the respondents thought that the 48-h window for calcium avoidance did not require strict adherence. The remaining 36 respondents (23.7\%) were undecided.

More than half of the respondents (93 [61.2\%]) stated that they had or would have a direct role in influencing their respective institution's official position on this issue. Within this subgroup, fewer respondents were undecided about the 48-h calcium avoidance window, with a greater proportion of participants (56/93 [60.2\%]) in disagreement and a smaller proportion of participants (17/93 [18.3\%]) in agreement.

A majority of respondents (99/152 [65.1\%]) reported that both ceftriaxone and cefotaxime were on their institutional formularies; $24(15.8 \%)$ reported that ceftriaxone was the only third-generation cephalosporin on their institutional formularies. About two-thirds of respondents (98/145 [67.6\%]) reported a change in policy regarding the administration of ceftriaxone as at least one of the ways in which their institutions had addressed the potential risk of ceftriaxone-calcium interactions; slightly fewer respondents reported the issuance of warning memoranda (84/145 [57.9\%]) and the implementation of a computerized alert system for pharmacists (79/145 [54.5\%]) (Figure 3). Only 21 (14.7\%) of 143 respondents described their institution's official position regarding the administration of ceftriaxone and calcium-containing IV solutions within $48 \mathrm{~h}$ of one another as an absolute contraindication. Conversely, 88 (61.5\%) participants described their institution's official position on this scenario as a relative contraindication, whereby the benefit may outweigh the risk in individual cases. Almost one-fourth (32/143 [22.4\%]) of respondents indicated that their institutions did not have a clear position on this issue.

Generally, removal of ceftriaxone from the formulary had not been considered as a response to the warnings (106/142 [74.6\%]), although 10 respondents did not describe the formulary implications at their institutions. Only 4 (2.8\%) of these 142 participants indicated that ceftriaxone had been removed from the formulary or was being considered for removal because of the warnings. Open-ended responses suggested that several institutions were attempting to curtail ceftriaxone use in favour of cefotaxime through adjustments to restriction policies and implementation of new auto-substitution policies. 


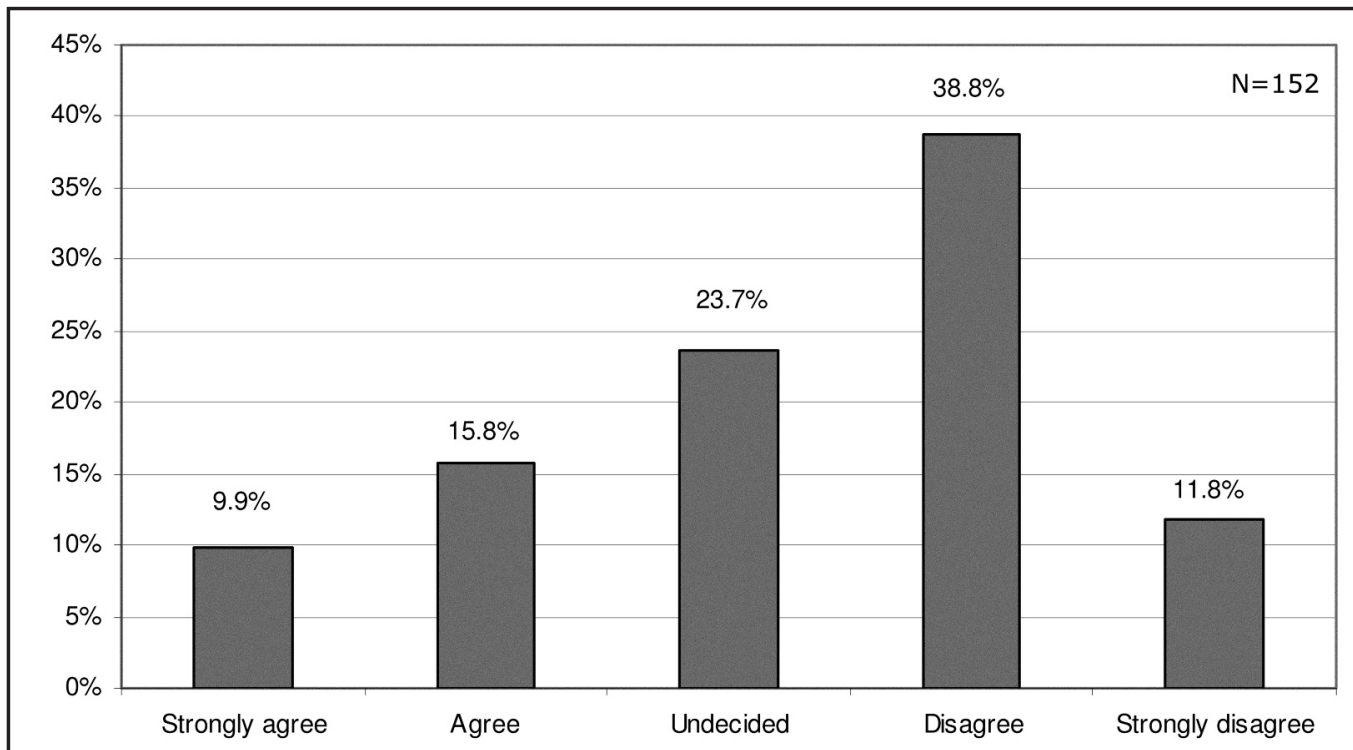

Figure 2. Respondents' agreement with 48-h window for avoidance of administration of ceftriaxone and calcium (IV) $(n=152)$.

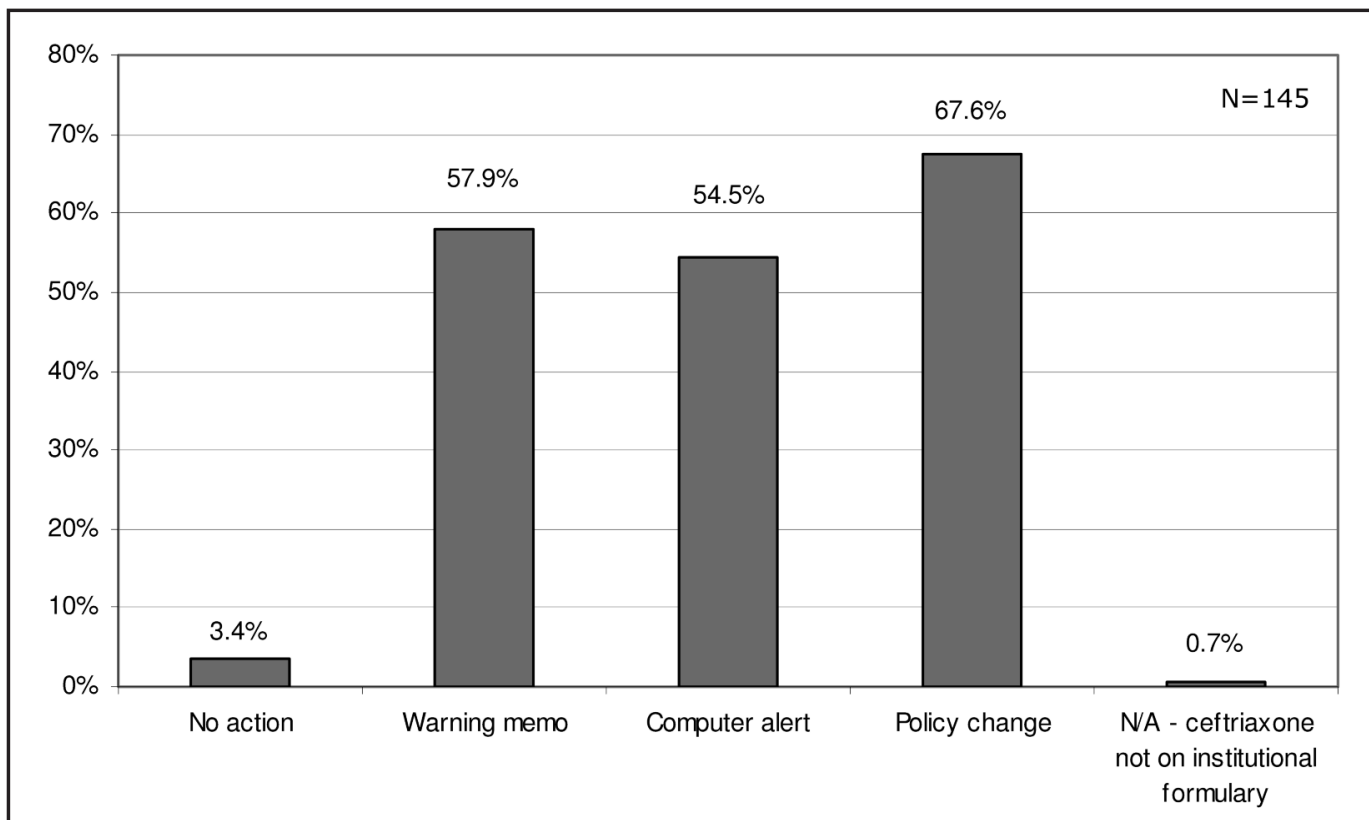

Figure 3. Institutional response to warnings issued by manufacturer and Health Canada $(n=145)$.

\section{DISCUSSION}

With its broad spectrum of activity against a number of key organisms, its safety profile, and its availability on the market for over 20 years, ceftriaxone has become an important antimicrobial that is prescribed and administered regularly by many clinicians. In view of the vast clinical experience with this agent and the fact that no cases of an intravascular interaction between ceftriaxone and calcium have been documented in adults, the warnings from Health Canada and the manufacturer about avoiding the concurrent use of ceftriaxone and calciumcontaining IV solutions has caused considerable concern among Canadian health care professionals. This concern was compounded by the fact that a reasonable alternative to ceftriaxone, cefotaxime, was unavailable at the time of the Health Canada Notice to Hospitals.

The survey described here assessed the views of pharmacy practitioners at institutions across the country. The results indicate that the warnings from the manufacturer and from Health Canada were of importance to hospital pharmacy 
practitioners. Almost all participants had an opinion about the warnings, with the vast majority being at least somewhat concerned. It was striking that half of the survey participants did not agree with a strict interpretation of the recommended 48-h window for calcium avoidance.

In Canada, ceftriaxone is not routinely used for neonates, as the availability of safer agents allows use of ceftriaxone to be minimized in this population. Thus, the section of the Health Canada Notice to Hospitals recommending avoidance of concurrent administration of ceftriaxone and calcium-containing solutions within 5 days of each other in patients less than 10 weeks of age is of minimal relevance. The second part of the notice, which recommends that ceftriaxone be avoided for $48 \mathrm{~h}$ in patients from all other age groups who are receiving calciumcontaining IV solutions, has proven much more disconcerting. It is likely that few would disagree with this recommendation as it pertains to coadministration of these agents through the same IV line or admixture bag; however, coadministration through separate IV lines and/or infusion sites and/or at different times within the 48-h window is a different matter.

Two main factors may have contributed to the disagreement and concern among pharmacy practitioners: the frequency of this combination of medications and the age of patients with documented interactions, as described in more detail below.

First, coadministration of ceftriaxone and calciumcontaining IV solutions within a 48-h period is relatively frequent. Ceftriaxone is commonly prescribed for adults and has a wide range of indications, including infections of the lower respiratory tract, upper respiratory tract, urinary tract, skin and skin structures, bones and joints, pelvis, and central nervous system, as well as intra-abdominal infections. ${ }^{9}$ Utilization of this drug for hospital inpatients has been quantified as 63 days of therapy per 1000 patient-days, which is less than that of cefazolin ( 94 days) and levofloxacin ( 75 days) but more than that of vancomycin (53 days) and piperacillin-tazobactam ( 43 days).$^{10}$ In a Toronto intensive care unit, ceftriaxone was the third most commonly prescribed antibiotic in the year 2000. ${ }^{11}$ Furthermore, calcium-containing IV fluids, such as total parenteral nutrition solutions and lactated Ringer's solution, are ubiquitous in the hospital setting and are often administered by continuous IV infusion. For many institutions, adherence to the 48-h avoidance window would be impractical and problematic and in theory might adversely affect patient care.

Second, the intravascular interactions documented to date have been limited to patients up to 1 year of age, who may be at risk because of the anatomic structure of their pulmonary vasculature, low volume of circulating blood, and prolonged half-life of the medication. ${ }^{7,12,13}$ Puzovic and Hardy ${ }^{14}$ mathematically demonstrated the stark differences between neonates and adults in weight-based dosing of ceftriaxone and calcium, with neonates potentially receiving 2 to 5 times the adult dose of ceftriaxone and 10 to 20 times the adult dose of calcium, with associated increases in the risk of precipitation. Notably, no difference in all-cause mortality was observed in a recent retrospective comparison of 465 patients who received concomitant ceftriaxone and calcium-containing IV solutions (i.e., within $48 \mathrm{~h}$ of each other) with 805 patients who received only ceftriaxone. ${ }^{15}$ Close to $90 \%$ of the patients in that study were adults. ${ }^{15}$ Subsequently, much discussion has focused on the appropriateness of extrapolating the risk of precipitation from the neonatal to the adult population. ${ }^{712-14}$

In the study reported here, almost $70 \%$ of respondents' institutions had changed their policies with respect to administration of ceftriaxone in response to the warnings. Conversely, only $14.7 \%$ of respondents indicated that their institutions considered the coadministration of ceftriaxone and calciumcontaining IV solutions to be an absolute contraindication. This may indicate that the impact of the Health Canada Notice to Hospitals on actual practice has been limited.

The limitations of this study should be considered in the interpretation of the results. The survey tool has not been validated and was intended for exploratory analysis. For the sake of timeliness, the questions were developed and the survey conducted within a relatively short period of time. The survey was intentionally brief to ensure the highest possible response rate, but this brevity came at the cost of not fully exploring the reasoning behind respondents' opinions. The sample size was relatively small, and the possibility of selection bias is inherent to the method used to solicit participation. We did not receive confirmation from all PSNs that participation in the survey had been solicited. Unfortunately, it was not possible to accurately determine the survey response rate, because individual respondents might have belonged to more than one PSN, and information about such overlap was not available. Limiting participation in the survey to practitioners belonging to one or more of the CSHP PSNs may have led to selection of a subset of practitioners who were most strongly affected by this issue. Also, the survey responses were from individual pharmacists, not institutions, which limited the ability to fully assess institutional responses to the warnings. The survey was conducted in English only, which may have limited responses from Quebec.

Despite strongly worded warnings issued by the manufacturer and Health Canada, only a small percentage of institutions represented by participants in this survey had changed their ceftriaxone administration polices to comprehensively reflect the warnings. Furthermore, the study results signify that the warnings are impractical and may not reflect the true risk among adults. Until more evidence for adults is available, a more reasonable warning might be that, in situations in which the benefit outweighs the risk, ceftriaxone 
may be used for patients receiving calcium-containing IV solutions, but only on a case-by-case basis, with careful clinical assessment performed each time the drug is administered.

\section{CONCLUSIONS}

There is disagreement within the hospital pharmacy community with regard to the strict interpretation of the 2008 Health Canada Notice to Hospitals about concomitant use of ceftriaxone and calcium-containing IV solutions. A large proportion of hospital pharmacy practitioners responding to this survey were concerned by recent warnings but did not agree with strict adherence to the recommendations issued by Health Canada, specifically as they pertained to a 48-h calcium avoidance window for non-neonatal patients.

\section{Note Added at Time of Publication}

The survey reported here was conducted to capture the opinions of Canadian hospital pharmacists about an important clinical issue as the situation was unfolding. On October 15, 2009, Health Canada issued a Notice to Hospitals regarding updated prescribing information for all ceftriaxone products marketed in Canada. This notice was based on 2 recent in vitro studies that showed an increased risk of ceftriaxone-calcium precipitates in neonatal plasma. Of note, new recommendations to replace those issued on July 31, 2008, specify that for patients other than neonates, ceftriaxone and calciumcontaining solutions may be administered sequentially if the infusion lines are thoroughly flushed between infusions with a compatible fluid. However, diluents containing calcium, such as Ringer's solution or Hartmann's solution, are not to be used to reconstitute vials of ceftriaxone or to further dilute a reconstituted vial intended for IV administration. Furthermore, ceftriaxone must not be administered simultaneously with calcium-containing IV solutions, including continuous calcium-containing infusions such as parenteral nutrition via a Y-site. Of note, mention of a 48-h calcium avoidance window has been removed.

\section{References}

1. Notice to hospitals: Health Canada issued important safety information on ceftriaxone. Ottawa (ON): Health Canada, Marketed Health Products Directorate; 2008 Jul 31 [cited 2008 Nov 18]. Available from: http://www.hc-sc.gc.ca/dhp-mps/alt_formats/hpfb-dgpsa/pdf/medeff/ ceftriaxone_nth-aah-eng.pdf

2. Andes DR, Craig WA. Chapter 22: Cephalosporins. In: Mandell GL, Bennett JE, Dolin R, editors. Principles and practice of infectious diseases. 7th ed. Philadelphia (PA): Churchill Livingstone; 2009. Available from: http://www.mdconsult.com/das/book/body/1672863384/0/2163/ 27.html? tocnode $=58026711 \&$ from URL $=27 . \mathrm{html} \# 4-\mathrm{u} 1.0$ B978-0-443-06839-3..00022-9--s0035_698. Subscription required to access content.
3. Bickford CL, Spencer AP. Biliary sludge and hyperbilirubinemia associated with ceftriaxone in an adult: case report and review of the literature. Pharmacotherapy 2005;25(10):1389-1395.

4. Martin E, Fanconi S, Kälin P, Zwingelstein C, Crevoisier C, Ruch W, et al. Ceftriaxone-bilirubin-albumin interactions in the neonate: an in vivo study. Eur J Pediatr 1993;152(6):530-534.

5. Information for healthcare professionals, ceftriaxone (marketed as Rocephin). In: MedWatch [reporting system]. Rockville (MD): US Food and Drug Administration; 2007 [cited 2008 Nov 18]. Available from: http://www.fda.gov/Drugs/DrugSafety/PostmarketDrugSafety InformationforPatientsandProviders/DrugSafetyInformationfor HeathcareProfessionals/ucm084263.htm

6. Shiffman ML, Keith FB, Moore EW. Pathogenesis of ceftriaxone-associated biliary sludge. In vitro studies of calcium-ceftriaxone binding and solubility. Gastroenterology 1990;99(6):1772-1778.

7. Monte SV, Prescott WA, Johnson KK, Kuhman L, Paladino JA. Safety of ceftriaxone sodium at extremes of age. Expert Opin Drug Saf 2008;7(5): $515-523$.

8. Important clarification of prescribing information. Nutley (NJ): Roche Laboratories Inc; 2007 Aug [cited 2008 Nov 15]. Available from: http://www.fda.gov/downloads/Safety/MedWatch/SafetyInformation/ SafetyAlertsforHumanMedicalProducts/UCM154852.pdf

9. Rocephin [product information]. Nutley (NJ): Roche Laboratories; 2007.

10. Polk RE, Fox C, Mahoney A, Letcavage J, MacDougall C. Measurement of adult antibacterial drug use in 130 US hospitals: comparison of defined daily dose and days of therapy. Clin Infect Dis 2007;44(5):664-670.

11. Yamashita SK, Louie M, Simor AE, Rachlis A. Microbiological surveillance and parenteral antibiotic use in a critical care unit. Can J Infect Dis 2000;11(2): 107-111.

12. Gin AS, Wheaton H, Dalton B. Clinical pharmaceutics and calciumceftriaxone. Ann Pharmacother 2008;42(3):450-451.

13. Rapp RP, Kuhn R. Clinical pharmaceutics and calcium ceftriaxone. Ann Pharmacother 2007;41(12):2072.

14. Puzovic M, Hardy G. Comment: Clinical pharmaceutics and calcium ceftriaxone. Ann Pharmacother 2008 [cited 2008 Nov 26];42(12): 1914. Epub 2008 Nov 25. Available from: http://www.theannals.com/cgi/ content/full/42/12/1914. Subscription required to access content.

15. Morrell M, Cannella C, Simpson S. Retrospective analysis of concomitant ceftriaxone and intravenous calcium administration at a university hospital [poster presentation]. Interscience Conference on Antimicrobial Agents and Chemotherapy and Infectious Diseases Society of America Conference; 2008 Oct 25-28; Washington (DC).

Curtis K Harder, PharmD, is with the Pharmacy, Vancouver Island Health Authority, Victoria, British Columbia.

John J Hawboldt, BSP, ACPR, PharmD, is with the School of Pharmacy, Memorial University of Newfoundland Health Sciences Center, St John's, Newfoundland and Labrador.

\section{Address correspondence to:}

Dr Curtis K Harder

Pharmacy

Vancouver Island Health Authority

1952 Bay Street

Victoria BC V8R $1 \mathrm{~J} 8$

e-mail: curtis.harder@viha.ca

\section{Acknowledgements}

We thank the members of the Executive Committee for the CSHP Infectious Diseases Pharmacy Specialty Network for their input in developing the survey. We also thank Dr Alfred Gin for his assistance in reviewing and interpreting the survey results. Finally, we thank all of the members of various CSHP Pharmacy Specialty Networks who participated in the survey. 
Appendix 1. Survey of Canadian pharmacists regarding response to warnings of potential interaction between ceftriaxone and calcium in IV solutions

1. In which province/territory do you practice?

2. Please describe the institution you represent.
Regional health authority
Teaching/tertiary care hospital
Community/general hospital
Other (please specify):

3. How concerned are you with the warnings issued by the manufacturer and Health Canada regarding the potential for an interaction between ceftriaxone and parenteral calcium-containing products?
Very concerned
Somewhat concerned
Don't have an opinion
Not concerned

4. Do you agree that the 48-hour calcium-avoidance window mentioned in the recent black box warning issued by Health Canada should be strictly adhered to?
$\square$ Strongly agree
Agree
Undecided
Disagree
Strongly disagree

5. Have you or will you have a direct role in influencing your institution's official position on the ceftriaxonecalcium interaction issue (e.g. through membership in a Formulary Task Group, Pharmacy \& Therapeutics or Antimicrobial Review Committee)?
$\square$ Yes
No
I don't know
Not applicable-ceftriaxone not on our institutional formulary

6. At what level have the manufacturer and Health Canada warnings been discussed in your institution (check all that apply)?
Pharmacy \& Therapeutics Committee
Antimicrobial Review Committee
Local Pharmacy Management
I don't know
Not applicable - ceftriaxone not on our institutional formulary
Other (please specify):

7. How has your institution addressed the potential risk of a ceftriaxone-calcium interaction subsequent to the manufacturer's and/or Health Canada warning (check all that apply)?

$\square$ No action has been taken

$\square$ A warning memo has been issued to healthcare professionals (in addition to the warnings issued by the manufacturer and Health Canada)

$\square$ A computer alert system has been implemented, notifying pharmacists of concomitant orders for ceftriaxone and calcium-containing products

$\square$ A change in policy has been made with respect to the administration of ceftriaxone (e.g. in the local IV monograph)

$\square$ Not applicable-ceftriaxone not on our institutional formulary

$\square$ Other (please specify):

8. Which best describes your institution's current official position on the administration of ceftriaxone and a parenteral calcium-containing product within 48 hours of each other?

$\square$ This is absolutely contraindicated

$\square$ This is relatively contraindicated (the benefit may outweigh the risk and clinical judgment must be made for individual cases)

$\square$ My institution does not have a clear position on this issue

$\square$ My institution may have a clear position, but I don't know what it is

$\square$ Not applicable-ceftriaxone not on our institutional formulary

$\square$ Other (please specify):

9. Which 3rd generation cephalosporin did you have on your institutional formulary before the ceftriaxonecalcium warnings?
$\square$ Cefotaxime
Ceftriaxone
Both

10. Which best describes the formulary implications (if any) that these warnings have had at your institution?

$\square$ Ceftriaxone has been removed from formulary Ceftriaxone formulary removal is being considered

$\square$ Ceftriaxone formulary removal has been considered but rejected (i.e. ceftriaxone to remain on formulary)

$\square$ Ceftriaxone formulary removal has not been considered

$\square$ Not applicable (ceftriaxone was and is not on formulary)

Other (please specify): 